\title{
Creating Inclusive and Equitable Cultural Practices by Linking Leadership to Systemic Change
}

\author{
Jovonnie L. Esquierdo-Leal \\ University of Nevada, Reno \\ Ramona A. Houmanfar \\ University of Nevada, Reno
}




\begin{abstract}
From a global pandemic to the killings of George Floyd, Breonna Taylor, Ahmaud Arbery, Rayshard Brooks and others in the Black community, the year 2020 has cast light on long-standing social injustices. With this has come a new social movement and a call for change. Specifically, a call for transformative solutions that address not only new challenges but centuries of systemic issues, such as systemic oppression and systemic racism. Leadership across the globe has scrambled to answer the call, some issuing statements committed to change, others engaging in necessary action. What is critical, however, is that leadership understands the cultural factors that have given rise to centuries of oppressive practices and that they are held accountable for the commitments they have expressed. Leadership must promote, create, and maintain prosocial, inclusive, and healthy work environments. This requires new cultural practices and a focused organizational model. Equally important is the need to resolve ambiguity and communicate effectively, with strategic consideration of constituent perspectives and needs. Therefore, the purpose of this paper is to discuss the contribution of behavior analysis in addressing systemic oppression as well as the pivotal role leadership communication plays in occasioning social change. It is our hope that this conceptual work will inspire behavior scientists to advance the field of behavior analysis and social movements in the direction of equitable, prosocial change that dismantles systemic oppression.
\end{abstract}

Keywords: Systemic oppression, racism, diversity, inclusion, equity, leadership, communication 
This manuscript is being published on an expedited basis, as part of a series of emergency publications designed to help practitioners of applied behavior analysis take immediate action to address police brutality and systemic racism. The journal would like to especially thank Associate Editor, Dr. Kaston Anderson-Carpenter. Additionally, the journal extends thanks to Mawule Sevon and Melody Sylvain for their insightful and expeditious reviews of this manuscript. The views and strategies suggested by the articles in this series do not represent the positions of the Association for Behavior Analysis, International or Springer Nature.

Guest Editor, Denisha Gingles 
A [person] who stands for nothing will fall for anything.

Malcolm X.

Researchers, policy makers, politicians, and concerned citizens have long been focused on creating and maintaining cultural practices that adequately address systemic issues: civil rights, income and asset inequities, mass incarceration, and many more. Unresolved, these issues have serious ramifications and require committed leadership and organization if change is to be initiated. It seems to be the case, however, that instrumental stakeholders (e.g., leadership, politicians, and large corporations) are rarely convinced a solution is necessary, even when an intervention is within reach. Moreover, when a leader is committed to addressing these issues personally, other stakeholders may prevent reform by imposing aversive consequences. This creates a divide among groups of individualsmany of whom claim to be guided by the same mission and aligned values-stalling necessary action and perpetuating systemic problems. Though diversity is critical to the success of any organization, the perpetuation of inequities and systemic oppression justified by the façade of ideological diversity has been the anchor preventing social movement for decades.

Many institutions have implemented policies to address systemic oppression, the inequitable treatment of specific social groups through laws, policies, and institutional practices. Yet, despite good intentions, these policies are often unable to overcome long-established oppressive practices. For example, to promote inclusive recruitment practices, academic institutions have implemented affirmative action plans-programs and policies that consider race and ethnicity as part of the evaluation of an application. One common finding across institutions is that there is much skepticism about the benefits of diversity, and many resist the idea of affirmative action plans (Herring, 2009). In fact, affirmative action plans have been so widely controversial, that 10 states have adopted bans, deeming them unconstitutional. Of note, is the effect these bans have had on marginalized students, decreasing their admission and enrollment in higher education (Long \& Bateman, 2020). Thus, efforts to 
redress centuries of oppression die at the hands of power structures and white fragility (DiAngelo, 2018), masked by the guise of constitutional rights, and reinstate inequitable practices that benefit those who oppose the policies in the first place. Unfortunately, it does not end there. Isms have been so long established in the United States - and worldwide for that matter - that "colorblindness" and "meritocracy" have become the public ideologies used to justify broken and discriminatory practices, hiding one's unwillingness to see problems for what they are: racism, sexism, ableism, and more. Accordingly, even when new policies and leadership rhetoric are formed to combat prejudice and discrimination, they produce the same outcomes, resulting in what is called preservation through transformation (Alexander, 2010).

The process of creating and implementing any systemic intervention requires careful research and planning, proper representation through genuine inclusion, and effective communication. One person alone does not initiate change and effective change does not transpire from the maintenance of the status quo. Communication is critical as it must impact both the development and implementation of policies, research, and behavioral skills. Additionally, communication must convince stakeholders (especially those with opposing views) and consumers to consider alternative approaches: approaches that influence change. Ultimately, leaders are positioned in the system to initiate meaningful change. Institutions require leaders that resolve ambiguity and communicate effectively, with intentional consideration of their constituents' perspectives and needs.

The purpose of this paper is to provide an analysis of the contingencies influencing both the speaker (leaders) and the listener (employees or constituents) in a series of verbal episodes, involving persuasion and related to systemic oppression. We discuss specific factors of behavioral systems (i.e., cultural milieu and institutional rule generation) and how they can influence and augment complex shared-functions among groups; specifically, how behavior analysis can promote prosocial behavior related to cultural change. It is our hope that this conceptual work will inspire behavior scientists to 
advance not only the field but social movements in the direction of equitable, prosocial change that dismantles systemic oppression. By drawing upon complementary perspectives, we will contribute to the literature in three ways: 1) by expanding the reach of behavior analysis and using it to discuss systemic oppression, 2) by discussing the interaction between social issues that have been addressed separately in the literature, and 3) by discussing the pivotal role leaders play in this process through organized and values-based communication.

\section{Why Diversity, Equity, and Inclusion Matter}

\section{Demographic Shift}

The United States is changing, both physically and demographically. For example, the U.S. census reported that in 1940, nearly 90 percent of the population identified as white. However, in 2010, the population had more than doubled and the percentage of those who identify as white fell nearly 20 percent (US Census Bureau, 2012). In another report, the US Census Bureau projected that between 2014 and 2060, the U.S. population would increase by approximately 98 million and with this would, again, come an increase in racial and ethnic diversity ${ }^{1}$. It has been argued that the nonwhite population will grow to $50 \%$ by 2050 and the non-Hispanic white alone group will fall below 50 percent, leaving no clear racial or ethnic majority² (Cárdenas et al., 2011; Colby \& Ortman, 2015).

Even with an increasingly diverse workforce, representation of marginalized groups has decreased in positions of power (McKinsey \& Co., 2004; Hill, Miller, Benson, \& Handley, 2016; Zarya, 2016). In 2016, fewer than four percent of CEO positions were held by Black, Indigenous, and People of Color (BIPOC; Gino, 2017), fewer than five percent were held by women, and fewer than three percent were held by women of color (Miller et al., 2016). Although recent data indicate representation has

\footnotetext{
${ }^{1}$ These population projections rely on assumptions about how mortality, birth rates, and immigration will take course over the next 30 years.

${ }^{2}$ In the context of race and ethnicity, the term minority carries patronizing hierarchical connotations. For this reason, the authors use the term, and related terms (i.e., majority), only when associated literature does so, and sparingly to reference changing demographics.
} 
improved, with "more progress in board representation for the Fortune 500 between 2016 and 2018 than between 2012 and 2016" (p. 7), we still see a consistently slow rate of change with $80.5 \%$ of board seats held by non-Hispanic white individuals (61.4\% men and $19.1 \%$ women; The Alliance for Board Diversity [ABD] and Deloitte, 2018).

In degree-granting, postsecondary academic institutions, with the exception of white women, data are similarly grim. Among full-time faculty in the Fall of 2017, 41 percent of faculty identified as men, while 35 percent identified as women; six percent identified as Asian/Pacific Islander (API) men, five percent as API women; three percent each identified as Black and Hispanic men and women, and fewer than one percent American Indian/Alaska Native (National Center for Education Statistics [NCES], 2019). These numbers become even more disproportionate when varied by rank. For instance, men and women who identify as Black, and men who identify as Hispanic account for two percent of full-time professors; while women who identify as Hispanic and all who identify as American Indian/Alaska Native make up one percent or less of full-time professors (NCES, 2019).

At the federal level, although the 2018 U.S. midterms resulted in record-breaking strides, representation in congress is still lacking. Despite an increase in the number of women elected to congress, seats are still disproportionately held by men. Specifically, white (77\%), straight (98.1\%), Christian (81.5\%), cisgender males (76.2\%) over the age of 35 (97.5\%; Morris, Adolphe, \& Salam, 2019). Conversely, who these individuals hire or provide training opportunities to is just as important. In a large-scale experiment focused on discrimination in hiring for top level administration in politics, Baekgaard and Georde (2018) found that among Flemish politicians, discrimination was mediated by ideological beliefs. Namely, ideological predispositions influenced applicant evaluations as well as reported inclinations to interview historically excluded and marginalized individuals. What is most disheartening about these findings is the potential silencing of these peoples' voices, or in many cases, the perpetuation of oppression. Oppression is exacerbated when an entire political group, which has the 
potential to affect policy change, is dominated by a homogeneous group. Although the abovementioned study is not specific to the United States, a 2018 report published by the Joint Center for Political and Economic Studies reported that only $13.7 \%$ of all top House staff positions (e.g., chiefs of staff, policy directors, and communication directors) were held by people of color. All of this considered, it is safe to conclude that diversity and inclusion efforts are essential. The lack of representation of BIPOC is present across institutional levels globally, and until the contingencies that maintain this practice shift, the overall population will not be adequately represented.

It is important to recognize that diversity in numbers alone will not suffice. Institutions must promote, create, and maintain prosocial (Houmanfar et al., 2015; Atkins et al., 2019), inclusive, and healthy work environments. Addressing representation, both passive and active, will influence whether the interests of all constituents and/or employees are considered in dialogue about policies and changes that affect those parties (Bradbury \& Kellough, 2011, pp. 158). Passive representation refers to the practice of employing individuals from underrepresented groups, in numbers proportionate to the population; while active representation ensures the voices and interests of underrepresented groups are not overlooked. The presence of both types of representation "is positively associated with bureaucratic outcomes consistent with the interests of the members of those groups" (Bradbury \& Kellough, 2011, p. 160). Therefore, the topic of representation needs to be at the forefront of workforce and labor conversations as it is central to the conversation about our changing demographics both within the U.S. and worldwide.

\section{Need for a Paradigm Shift}

Although much of the focus on diversity in the workforce has been limited to a legal context (i.e., discrimination and harassment policies or laws), it is argued that the aforementioned 
"demographic shift will hold important policy implications, particularly if current racial and ethnic disparities in education, employment, health, and other social services continue. If we do not ensure the success of the most vulnerable among us moving forward, then we will prevent the United States from fully capitalizing on the global economic advantages we can derive from our increasingly diverse population." (Cárdenas et al., 2011, p. 1).

Marginalized groups such as BIPOC experience "significant obstacles and disparities," and this will only continue (Cárdenas et al., 2011, p. 1) unless effective policies and interventions are implemented. The development and implementation of effective policies and interventions that terminate and/or ameliorate human suffering and oppression is unlikely if marginalized groups are not actively involved in their development. Moreover, policy-makers and researchers invested in employing social interventions should avoid colonial or exploitative relationships with the target population (Fawcett, 1991), where colonial relationships refer to "the economic, political and cultural domination of one cultural-ethnic group by another" (Omvedt, 1973, p.1). An understanding of how interventions may impact these communities in the near and long run is essential. Good intentions can have harmful effects, some of the most obvious examples being gentrification and homelessness. In addition, as U.S. demographics shift-leaving no clear racial or ethnic majority-so does the marketplace. It is possible that consumer choice and demand will shift resulting in the selection of organizational practices and products that meet the needs of a diverse population. Yet, this does not mean that power will be acquired by marginalized groups. The danger of unchecked capitalism always looms, as the affluent few have the resources to capitalize on cultural practices and objects. Capitalist practices, such as rebranding cultural products for a profit (appropriation) and gentrification, do not serve citizens but instead profit the wealthy. Unchecked capitalism is integrally connected to social and economic inequality, exploitation, and marginalization (Davis, 2016), making it an issue leaders must address (Biglan, 2020). 
In much of the organizational behavior management (OBM) literature, one of the primary focuses of analyses and interventions is the added financial value (Brethower, 2000; Gilbert, 2007; Houmanfar et al., 2015). The financial marketplace and the consumer marketplace interact in a strictly monetary fashion: the organization works to maximize financial gains, the employee works to earn a living, and the consumer tries to get more "bang for a buck." Houmanfar et al. (2015) suggest that "the main challenge of organizations in the 21st century is to interact with increasing environmental demands that are not only financial but also social in nature" (p. 18). That is, organizational leadership should consider the socio-political climate and the values of consumers/constituents. This demonstrates to the consumer that though financial gains are essential to the organization's survival, social values are simultaneously considered. Organizations that speak to this balance, "demonstrate that social values can trump public displays of affluence" (p. 21). Moreover, Houmanfar et al. (2015) argue that the emphasized concordance between financial and social value should exceed a present moment perspective, by considering the entire population and their needs, which is one step in the right direction.

\section{The Role of Leadership in Influencing Social Change}

The clarion call for effective leadership is no stranger to behavior analysis (Mattaini \& Aspholm, 2016; Houmanfar et al., 2015; Houmanfar \& Mattaini, 2016); the need for an effective technology to address societal ills has been present in the literature since the inception of our science (Skinner, 1938; 1948). More recently, Houmanfar and Mattaini (2016) emphasized the role of leadership in constructing nurturing, just, and reinforcing societies (p. 43), and as recent events show (e.g., the long list of lives taken at the hands of police brutality and the separation of families at U.S. borders), we are well past due for this construction at all levels. Addressing the resurgence of explicit prejudice and discrimination (ADL, 2020) has become both a moral and ethical obligation. In order to address these issues, leadership will need to construct and implement a new progressive movement (Mattaini \& Aspholm, 2016)-a 
movement that goes beyond piecemeal approaches and into analyses that allow them to address the complex system that gives rise to oppressive cultural practices. Equally significant is the understanding of the complexity of systemic oppression and how it deeply connects to other social struggles. For instance, systemic oppression has long forced a number of social groups-specifically, those of low socioeconomic status (SES) and BIPOC-into overcrowded, poorly maintained neighborhoods. These neighborhoods are most vulnerable to dangerous crises (e.g., oil spills and hurricanes; Tierney, 2012) and have been shown to be disproportionately exposed to air pollution (Tessum et al., 2018) and infection and disease (NIH, 2018).

\section{Intersecting Social Issues}

Decades of research has documented the relationship between social inequities and disaster vulnerability. In reviewing the factors that contribute to vulnerability and resilience in disasters, Tierney (2006) stresses the importance of recognizing "disaster vulnerability as a function of both physical place and social conditions" that increase the likelihood of harm and ability to cope. For example, at the time Hurricane Katrina hit Louisiana, New Orleans was physically vulnerable with its below sea level elevation and proximity to the Gulf of Mexico. Additionally, prior to the hurricane, it had become a majority Black and poor city, with few employment and educational opportunities. Therefore, "a large proportion of the population of New Orleans was highly vulnerable, both on an everyday basis and with respect to extreme events'” (Cutter, 2005, p. 112). This research lends urgency to the importance of proactive policy work, especially since disaster-relief has historically been inequitably distributed and/or blocked for political interests.

Researchers have found that race, class, and gender-which intersect at various points-are correlated with lower levels of post-disaster resilience: that is, the handling of insurance applications, the distribution of business loans, resident displacement, and monitoring of relief resources (Tierney, 2012). For example, Hurricane Katrina exposed existing inequities that manifest leading up to and 
following disasters in the United States. The state and federal response to Hurricane Katrina demonstrated that leadership had not actively considered the needs of a marginalized and underresourced community when preparing policies and strategies for disaster relief. Katrina was by no means an isolated occurrence. A year after the catastrophic Hurricane Harvey hit the coast of Texas, survey research suggested those in the poorest afflicted areas were struggling to recover, and people of color reported that they were not receiving necessary aid (Hamel et al., 2018). In the same vein, following the devastation of Hurricane María, though governmental aid was provided to the island of Puerto Rico, it fell short of what was necessary to recover (Melendez \& Venator-Santiago, 2018). Furthermore, years later, corruption among local Island governance was revealed. Funds were misallocated and mismanaged, disaster supplies were hidden, and a lack of empathy for the diverse Puerto Rican community was made evident through the release of governmental communication (Romo \& Florido, 2020; Melendez \& Venator-Santiago, 2018; Ardila et al., 2019). The choices leadership made both at the governmental and local level clearly demonstrated that action is too often guided by personal values and not those of the overall population.

The recent COVID-19 pandemic has further exposed long-standing health disparities. Emerging data suggest that non-Hispanic Black, Hispanic and Latinx, and Native American and Alaska Native persons have higher rates of hospitalization and death due to COVID-19. The Centers for Disease Control and Prevention (2020) report that non-Hispanic Native American, Alaskan Native, and Black individuals are hospitalized at a rate five times that of non-Hispanic whites; and Hispanic and Latinx persons are hospitalized at a rate four times that of non-Hispanic white individuals. In addition, data suggest these groups are more susceptible to other infections and diseases (NIH, 2018), increasing their risk of contracting COVID-19 (CDC, 2020). Even more discouraging is the fact that these trends are not new; "history shows that severe illness and death rates tend to be higher for racial and ethnic minority populations during public health emergencies than for other populations" (CDC, 2020). Health and 
health care disparities are influenced by many factors (e.g., access to health care, occupational exposure, quality of care), and leadership is responsible for promoting proactive, counter-hegemonic conversations that transform policy for groups exposed to additional harm.

Instrumental decision-makers and policy teams hold critical functions and should be privy to the literature demonstrating the relationship between social inequities and other social issues (e.g., climate change; Islam \& Winkel, 2017). At the same time, these leaders need to understand that they influence the processes that contribute to these struggles, which means they need to be active in reconstructing them. When instrumental stakeholders and administrative leaders are educated on large-scale social trends, structural forces, group characteristics related to preparedness for, responses to, and recovery from disasters, appropriate policies and governance can be implemented. Thus, it is critical that educational institutions not only model prosocial leadership, but also prepare future leaders to think critically about systemic issues. The bulk of literature on leadership focuses on common characteristics, habits, and team building, but rarely does it focus on systemic approaches to addressing critical factors at the group and individual level. As highlighted by Mattaini and Aspholm (2016), "we are in the midst of a period in which global change will be required if societies and many species, perhaps even our own, are to survive" and "it is hard to imagine a time when effective leadership is more necessary or will be more challenging" (p. 109).

\section{Leadership Repertoires}

When complex and seemingly unresolvable problems (i.e., wicked problems; Levin et al., 2012) manifest, a ubiquitous reaction is to look for historical examples of resilience and intervention. A remarkable amount of research centers on the identification of leadership skills that may accomplish effective social change. By studying history and a number of influential leaders such as Ida B. Wells, Rosa Parks, Martin Luther King, Jr., John Lewis, Nelson Mandela, César Chávez, Angela Davis, and Tarana Burke-to name a few-researchers have identified a plethora of characteristics common to effective 
leaders. Malott (2016), for instance, identifies four characteristics of great leaders: commitment to principle independence, resilience, and consistency. Similarly, Krapfl and Kruja (2015) outlined a menu of leader behaviors, briefly highlighting the importance of communication skills across three aspects: communication of a bigger picture as it relates to an assigned task, clear communication, and listening.

Outside of behavior analysis, research has focused on the leader trait paradigm (Judge et al., 2009). With varying models or conceptualizations, the leader trait paradigm analyzes varying personality traits that make leaders effective, giving rise to personality tests and career assessments, such as the

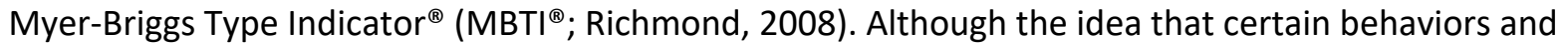
traits make someone more effective is supported by a vast body of literature, isolating particular behaviors and traits does not acknowledge context. We argue that a holistic perspective, with an eye on the functional relations between environment and behavior across time and context (Hughes et al., 2012, pp.22), would offer a more comprehensive approach toward cultural change. Moreover, the role of leadership communication as well as collective organization (Mattaini, 2013) pertaining to cultural change are worthy of further discussion.

Prosocial leaders serve a critical function in large behavioral systems. When they understand their function and ways their decisions impact the behavioral system, they can be more successful in constructing change. Thus, we argue that a leader's efficacy is defined in context. Knowing about overlapping issues impacting members of society, with intersectional identities (Crenshaw, 1989), allows leaders to take a systemic approach to interventions, coordinating prosocial action within and across organizations. Additionally, they are able to create a culture of inclusiveness through shared identity and values (Atkins et al., 2019), empowering members within the group and mobilizing efforts through collective leadership. 
A recent recommendation by Mattaini and Holtschneider (2017) suggests collective leadership is necessary to address wicked problems. An analysis of social movements reveals that social justice work is rarely dependent on a single leader; "a densely interconnected network of leadership," also called collective leadership, is critical (Mattaini, 2013, p. 121). Collective leadership may refer to social movement organizers, student organizers, academic faculty, people joining together to form unions, policy makers, and more. As organizers who operate across various levels of an organization, these individuals have the potential to influence both the masses and those who occupy the top position in the organizational hierarchy (i.e., centralized leadership). This is especially likely when centralized leadership fails to adequately address systemic issues. That being said, the mobilization of collective leadership does not always come from the top; it may transpire from ineffective practices and conflict within an organization (e.g., inequitable pay, unsafe conditions, and poor communication) that mobilizes employees or constituents, thus giving them power. After all, effective prosocial organizations should rely "on processes of shared power in which all voices are respected in deliberations and on established procedures to make decisions after all voices have been heard and to maintain discipline around those decisions, once made" (Mattaini, 2013, p. 129).

The problem of power relations in any institution or organization (e.g., religion, education, government, or sciences) has to do with control, coercion, or dominance of individuals operating under institutional contingencies (Foucault, 1982). In these sorts of relations, the exercise of power does not necessarily imply the absence of freedom. There is always the potential for individuals within the institution to influence one another (Foucault) - that is, the ability to collectively organize (Mattaini, 2013). Thus, freedom exists, albeit at varying levels, so long as alternative choices for reinforcement, and in some cases, countercontrol are available (Goltz, 2020). As such, the focus of analyzing social issues, such as systemic oppression, should not be in conceiving freedom from oppressors but rather on shifting the balance of who is holding or exercising power through collective leadership. Until then, 
systemic contingencies that maintain the status quo (i.e., power held by dominant groups) will survive through cultural hegemony (Gramsci, 1971).

\section{Cultural Milieu and Systemic Change}

Styles of leadership and management are believed to function as important factors in design and implementation of effective organizational contingencies. Leadership communication networks affect ways by which coordinated or organized practices of organizational members bring about the generation of emergent products that in turn influence cultural milieu. For instance, leadership and management practices may promote conflict among members of an organized group through environmental ambiguity that is defined as incomplete or inaccurate information regarding the workrelated matters that lack clear or accurate description of contingencies and their context (Houmanfar \& Johnson, 2003).

As discussed in the recent culturo-behavior scientific literature (Houmanfar et al., in press; Ardila et al., 2019; Houmanfar et al., 2010), cultural milieu consists of contextual factors influencing the acquisition and maintenance of the collective behaviors of individuals interacting with the associated aggregate products (i.e., what is produced by the group). The design of a product and its generation rely not only on selection by consumers but also on the cultural milieu which consists of the prevailing beliefs and values within the culture as well as predictions about the future. Institutions and product designers study market trends and create consumer demand. In much the same way that rules can govern behavior before that behavior comes into contact with contingencies, societal values and beliefs about the future-be it the economy, a richer middle-class, the competition, advocacy organizations, or other factors - can also guide the design of organizational products or provision of human services, which consumers may or may not select or purchase. This relationship can be circular in that the consumers' interaction with products and services often alter the cultural milieu resulting in a different 
set of strategies for organizational practices. For example, Facebook has revolutionized access and sharing of information and created an online marketplace plus media platform that retailers and media networks have utilized. Though touted for its benefits of enhanced communications and information sharing, the influence on presidential elections in 2016 via its shadowed use by special interest groups, and foreign forces has negatively influenced Facebook's image among some users, and tarnished consumer trust. This transformational change in the cultural function of Facebook has also negatively affected users' confidence in social network platforms as venues for sharing trustworthy information.

As institutions move toward values-based practices, they hold themselves accountable to creating organizational processes that better serve the communities they are a part of. Behavioral products such as texts, television shows, music, and art establish new relations among stimuli and evoke stimulus substitution and derived relational responses. When members of society are exposed to television shows depicting the same family dynamics, the same identities for certain professions, and the same identities for deviant or socially unacceptable events, verbal functions that participate in relational responding are established (Hayes et al., 2001). Therefore, behavioral products replicated by various groups and organizations, influence the cultural milieu and the cultural milieu influences behavior at the individual level. The relation in any system of analysis is not linear, every component interrelates.

Dismantling the racist and oppressive components of the cultural milieu that in turn will influence systemic change will require critical masses. Leadership will serve as a catalyst in this process, orchestrating teams to identify points of intervention across systems (Houmanfar et al., 2010; Mattaini, 2013). Doing so will permit the institution to move beyond piecemeal approaches and into systemic strategic interventions guided by shared community values. Even more important is the need for leadership to transcend performative allyship and create a culture of inclusive accompaniment (Farmer, 2011; Fulambarker, 2016) through values that motivate the collective group to dismantle years of 
oppression and racism. Moreover, the literature indicates that level of environmental ambiguity

produced by leadership communication negatively affects group cooperation and increases resistance to change (Houmanfar, Rodrigues, \& Smith, 2009; Houmanfar \& Johnson, 2003; Kolvitz, 1997). All of this requires careful and strategic communication, a challenge that behavior science is equipped to exercise. In that regard, in the remaining sections of this paper, we will explore how understanding communication networks and the nature of verbal rules may contribute to understanding the issues involved in re-engineering behavioral systems in the face of continued socio-economic and cultural demands. This discussion will include an analysis of leadership and the associated roles in relation to communication networks in organizations.

\section{Organized Communication for Systemic Change}

\section{Communication and Leadership}

One important skill common to both leaders and effective social movements, within and outside of institutions, is communication. The role of communication has become "a common thread in behavioral [accounts] of leadership" (Houmanfar \& Rodrigues, 2012), some placing emphasis on how institutional rule generation can achieve change; others focusing on persuasion, which may also include rule generation from a behavior analytic perspective. Words, carefully crafted, are one of our greatest weapons against systemic oppression and racism, as they open a window onto others' realities. Therefore, leaders are often in critical positions to not only pinpoint how interrelated systems can be addressed, but also to learn how verbal behavior can be used to move communities to intervene on the oppressive systemic practices that have been upheld for centuries.

\section{Institutional Rule Generation}

Though the study of rule-governed behavior is not new to behavior analysis, recent conceptual and experimental analyses have expanded its relevance to the analysis of leadership communication. Pelaez and Moreno (1999) propose the "concept of rule-governed behavior can be useful if it 
accommodates the description of complex behavior that is under the control of contingencies and can be modified by antecedent verbal stimuli (i.e., rules)" (p. 21). Moreover, they suggest the function of a rule is to influence listener behavior. How the rule is communicated (i.e., through statement and rhetoric) to the listener(s) influences how listeners will respond (Ghezzi et al., 2020; Johnson et al., 2010; Rafacz et al., 2018; Smith et al., 2011; Smith et al., 2011).

Expanding on the work of Pelaez and Moreno (1999), and examining rules from a Relational Frame Theory (RFT) standpoint, Houmanfar et al. (2009) draw attention to the importance of communication networks. They suggest that "leaders have to take into consideration the ever-evolving external environment and verbally evaluate the potential adaptations the organization can make to [the possible future]," and in doing so, "account for conflict of human values" (p. 270). Related to the foregoing discussion pertaining to factors influencing oppressive and racist cultural practices, leaders must fully analyze the system they are a part of, the feedback selecting their institutional practices, and the direction they would like to move toward in order to generate institutional verbal stimuli, such as rules (e.g., organizational policies, bylaws, and values).

According to RFT, individuals learn to respond to a stimulus based on its relation to other stimuli. The ability to relate stimuli based on non-physical, arbitrary properties is termed arbitrarily applicable relational responding (AARR), and is central to many of our everyday interactions. AARR, to be referred to as relational responding for the remainder of this paper, occurs in varying patterns given one's history with particular contextual cues (see Barnes-Holmes et al., 2020; and Barnes-Holmes et al, 2017 for a full account), and it is the hyper-dimensional, multi-level (HDML) dynamics of this type of verbal behavior that make communication complex. Through ongoing interactions with our social communities, we are able to learn to engage in a range of relations with varying implications. Relational responding can involve simple relations between just a few events (relating at one level) or relations between entire networks of events (another level). In fact, it is what lies "at the core of metaphor, 
allegory, anecdote, and parable (Hayes et al., 2001, 74). Further, it is through relating, under the control of arbitrary contextual cues, that functions of one event (or relational network) transform related stimuli/events (people, places, and objects). Hence, the simple action of labeling a particular social group as "different," has the potential to transform the functions of that group, stimuli related to that group, and anyone who identifies with that group. Considering stimulus functions are influenced by socio-cultural practices upheld over centuries (i.e., the cultural milieu), many groups labeled as "other" have wrongfully ${ }^{3}$ acquired stimulus functions that evoke hateful and racist behavior (e.g., racial slurs). This defining feature of language, the transformation of stimulus functions, lies at the center of racism, permitting the development of a broad and harmful repertoire.

It has been argued that since verbal stimuli (i.e., stimuli participating in relating) acquire psychological functions, some consequences do not have to be directly contacted to influence behavior (Hayes et al., 2001). In considering contextual control over the transformation of stimulus functions, rules, "in a less technical way,... [ensure] contact with a domain of events" (Hayes et al., 2001, p. 108), such as verbally constructed consequences. In the RFT literature, three types of rules are defined: plys, tracks, and augmentals. All three are useful in organizational rule generation and communication on the part of leadership. We will discuss augmentals as they relate to persuasion.

\section{Persuasion}

Although the phenomenon of persuasion has not been especially common to the literatures of behavior analysis, a vestige of early work can be found in social psychology, and more recently, in behavioral accounts of language (see Table 1). For instance, Aristotle's term ethos, refers to the character of the speaker and contributes to their social influence- how credible, eloquent, and well versed the speaker is. In social psychological literature, Cialdini (2011) reinvents this concept through

\footnotetext{
${ }^{3}$ While we recognize the importance of using technical terminology, in this case, wrongfully refers to the overgeneralization of certain properties based on learned stereotypes.
} 
the principle of authority, which refers to the importance of the speaker. In behavior analysis, researchers have considered speaker variables by referring to the credibility of the speaker (Hayes et al., 2001; Houmanfar et al., 2009). These conceptualizations have permitted the study of persuasion as a repertoire, enabling the identification of persuasive tactics that may be utilized to mobilize communities.

Elaborating on social psychological definitions and influenced by the work of behavior scientists, such as Mattaini (2013), we define persuasion as the use of verbal stimuli (i.e., vocal, written, auditory) to influence or move a listener's behavior toward preconstructed values, either individualized or shared. An emphasis on listener values or on the listener-speaker's shared values is necessary, since in some cases, persuasion is used unethically. This is not to be confused with coercion, which relies on the implementation of aversive consequences and is more likely when power holders are less skilled at using their power in noncoercive, nonaversive, or nonexploitative ways ${ }^{4}$ (Goltz, 2020, p. 140). In the present formulation, we maintain that persuasion, of any form, differs from coercion when the speaker is not in a position (of power) to influence behavior through the implementation of aversive consequences. For example, pointing to effects of climate change may draw attention to aversive contingencies, but the speaker may not be the one who has influence over those contingencies. Further, the listener is free to choose to engage in values-based action. Recognizing the deterministic doctrine guiding most behavior analytic research, in this sense, freedom refers having access to resources and alternative responses that permit the individual to genuinely choose to take action in the absence of coercion or punishment (Baum, 2017; de Fernandes \& Dittrich, 2018; Goldiamond, 1965, 1974/2002, 1975a, 1975b, 1976). Furthermore, a genuine choice is one in which "critical consequences are available for different behavioral patterns" (de Fernandes \& Dittrich, 2018, p. 12). To focus on the need to address inequitable

\footnotetext{
${ }^{4}$ On average, police departments require 651 hours of basic training prior to joining the police force (Institute for Criminal Justice Training Reform, 2020). A call to action to expand the "self-improvement" category in police academies was published by Blumberg et al. (2019), but it is likely that police officers do not get enough training to learn useful communication skills.
} 
systems, we use the term prosocial persuasion when the speaker works to align speaker-listener values, in order to construct shared values that relate to community wellness and benefit. Achieving prosocial behavior change through prosocial persuasion requires skill and a greater understanding of the principles of persuasion.

Cialdini $(1984 ; 2016)$ formulated one of the most recent and prominent accounts of persuasion. Influenced by early literature and personal experimental endeavors, Cialdini developed six principles of persuasion: authority, consistency, reciprocation, liking, social proof, and scarcity. These principles are comprised of multiple strategies and are collectively called weapons of influence, since they are carefully constructed to evoke desired behavior. Furthermore, it is argued that an individual who a) uses these principles, b) understands when to use them, and c) with whom, will be most effective at crafting a persuasive statement (Cialdini, 1984). Considering the robust line of research that this work has generated, Cialdini has provided a solid framework for researching the phenomenon of persuasion. More importantly, each of his principles, can be understood from a behavior analytic lens, placing focus on skills leaders can utilize to evoke prosocial behavior. To highlight a few, let us consider two of these principles.

First, the principle of consistency relies on the assumption that humans desire to be as consistent with existing commitments or behavior as possible (Cialdini, 1984). Similar to Aristotle's model of logos (See Table 1), consistency has been exemplified through a tactic called the foot-in-thedoor approach, where a speaker makes a small request in preparation for a larger one. According to this principle, if the listener has already complied with a small request, they are more likely to comply with a larger request. A behavioral account could explain this principle using literature on behavioral momentum, a metaphor that refers to the establishment of compliance when high probability requests are followed by low probability requests (Nevin, 1996). The effectiveness of this strategy has been 
demonstrated across various contexts, including high intensity situations such as hostage negotiations (Hughes, 2009).

Second, based on the finding that "people say yes to those they owe" (Cialdini, 2016, p. 153), the reciprocity principle suggests that listeners are more likely to comply under conditions in which the speaker/requester has already provided the individual with a gift or good of some sort. To illustrate, consider the example of taking a trip to the grocery store: Costco Wholesale Corporation will often provide samples to its customers with the intent of persuading those customers to buy the product they are sampling. Cialdini (2016) describes this effect by suggesting individuals feel obliged to return a favor. However, a closer look at behavioral literature can provide a supplemental explanation through reinforcer sampling and motivative augmenting (Hayes et al., 2001). Ayllon and Azrin (1968) conducted several experiments that implemented a reinforcer sampling procedure to increase the reinforcing value of activities available to patients in a treatment facility. In short, the researchers set up conditions that prompted the patients to sample activities before being presented with the opportunity to fully engage in the event. The results of the study suggested that when the reinforcer sampling procedure was implemented, more patients selected the activities as reinforcers, and patients who had already been selecting the activities did so more often. These findings indicate that merely a brief exposure to an event or tangible item can alter its reinforcing value and the frequency of relevant behavior. Of note here, is the argument that motivative augmentals operate in a similar manner, a concept we will cover in more detail below. Their effect, however, is achieved through derived relations and transformed functions instead of direct sampling (Hayes et al., 2001). This concept explains how verbal stimuli may present motivating functions of various consequences, evoking target behavior. For example, statements that emphasize prosocial values, or documentaries about the trafficking of Indigenous women, may bring human suffering into psychological proximity occasioning prosocial behavior. 
In developing a persuasive message, one must consider its function and how the message aligns with the values or history of the targeted audience. Mattaini (2013) suggests that in most cases, this can be accomplished by "offering or clarifying incentives for changing behavior in specific ways." Additionally, he posits that "nearly every campaign requires action that is intended to increase motivation for the struggle among the population and within the resistance group" (e.g., Black Lives Matter; Mattaini, 2013, p. 170). Therefore, leadership should establish rules that shift motivation. One such way is through the use of motivative augmentals (motivational statements), rules that "alter the degree to which previously established consequences function as reinforcers or punishers" (Hayes et al., 2001, p.109). Drawing upon RFT, we will discuss three ways this can be accomplished.

When a leader generates persuasive and/or motivational statements, they emphasize established or verbally constructed consequences that appeal to the listener's values and reinforcers (Hayes et al., 2001). For example, in advocacy work aimed at establishing mentorship or pipeline programs, one might consider reaching out to educational leaders with a message like, "You mentioned that as a first-generation college student, you have come to value education because it continues to offer opportunities for growth. Children in our community need mentors and role models like you, who can teach them to love learning. Are you willing to give back to your community?" This message highlights a previously constructed value of education and potentially increases related behavior such as donating time, resources, or money. Another effective tactic might be to highlight incoherence (Hayes et al., 2001). Consider the title Powell (2020) used in a recent blog: "All lives can't matter until Black lives matter too." In eight words, the title highlights incongruent relations and elaborates on already established relations. Many people say they value all lives; however, by perpetuating systemic racism, regardless of intention, they are not demonstrating that they value all lives-certainly, not Black lives ${ }^{5}$.

\footnotetext{
${ }^{5}$ Considering the origins of the phrase, "all lives matter," we acknowledge that it is often used to dismiss the Black Lives Matter movement. The purpose of this example is not to reduce the complexity of its usage or to discuss intention but to provide an example of incoherence.
} 
This form of motivative augmenting is similar to the concept of cognitive dissonance-a term used to describe the psychological discomfort one feels when cognitions or actions are incoherent (Festinger, 1957) - but places a heavier emphasis on incongruent verbal relations. Finally, the "simplest form of rhetoric involves the weakening of psychological functions maintained by verbal relations (Hayes et al., 2001, p. 204). This has far-reaching implications as it is built around the premise that relations are not directly eliminated; instead, one transforms the functions of the stimulus in question through the establishment of new relations. Thus, if a person learns stereotypes about a group of people, simply saying that the stereotype is incorrect may not be effective ${ }^{6}$. Verbal relations are altered through exposure to alternative pieces of information that are inconsistent with previously established relations and can be verified through direct and indirect experiences. This exposure may require special attention since the dimensions of rhetoric are just as pertinent as the need to carefully craft the message.

When the occasion to act and bring together a community to address important social issues arises, critical dimensions of persuasion such as the source of the message, the timing, and the medium/form are important for leadership consideration. Source refers to the person conducting the delivery of a given message. Though every organization has leaders, as described above, credibility is essential. For instance, a university's president may be called a leader, however, in some cases groups of well-respected academic faculty and deans may have the greatest impact among other faculty and staff. Second, how frequently leaders allude to values, mention a particular issue in a speech, or offer opportunities for community members to engage is critical. By simply attending a church sermon or speech given by a political candidate or activist, one can bear witness to the ways in which points are repeated and emphasized for added effect. For illustrative purposes, let us briefly consider one of the most iconic addresses in history: the address Dr. Martin Luther King Jr. delivered at the Lincoln

\footnotetext{
${ }^{6}$ This idea also relates to the issue researchers have pointed out regarding cultural competence training, where associating groups of individuals with certain cultural practices may perpetuate stereotypes (Stone \& Moskowitz, 2007; Esquierdo-Leal et al., 2020).
} 
Memorial in 1963, titled, I Have a Dream. In one small section, Dr. King repeated the statement, "I have a dream" eight times, followed by ten repetitions of the words, "let freedom ring." Dr. King, as one of the most influential individuals known to the civil rights movement, was able to appeal to his audience's experiences, values, and dreams in just a few minutes through the power of words. Lastly, the medium or form of the rhetoric should thoroughly be considered. Some advocacy leaders use audio in the form of podcasts, others use printed stories and art. One of the most unique and interesting abilities known to human organisms is their verbal repertoire; specifically, their ability to tell stories across mediums and through art. In a TedX talk, Dr. Tammy Brown describes art as a weapon for social change (Brown, 2014). We agree with this statement and suggest that art as a verbal stimulus, whether it be through paintings, music, poetry, or narrative, has the power to occasion values-based action.

\section{Narrative}

Story-telling and narrative can be traced back, as a cultural practice, to the beginning of human social interactions. It has provided comfort in times of darkness, knowledge in times of need, and motivation in times of struggle. Narrative and persuasion have also been key skills lawyers use in the courtroom, and critical race theorists have emphasized their usefulness in building a case (Delgado, 2017). As described in detail above, those looking to alter verbal relations can present new information through counter-storytelling, altering already established relations. Furthermore, storytelling can be the "cure for silencing" (Delgado, 2017, p. 20), giving marginalized or disenfranchised groups a voice; and, in some cases, empowering those who feel isolated or feelings of blame related to their situation, to learn that they are not alone in their suffering. Many of the persuasive skills already discussed are fundamental to narrative, however, one form of narrative that has not been given due diligence is narrative on canvas (or any other surface). Malott (2019) provides a detailed account of the interlocking behaviors of muralists and painters that occasioned a cultural cusp, the muralist movement; however, to date, murals as stories that serve as motivating variables for prosocial action, have not been discussed. 
In the time of social media and the ability to use technology for social change, it would behoove any leader to consider this form of narrative in their communication.

A drive down the streets of East Los Angeles provides some of the most vibrant and moving pieces of art one could encounter. With each paint stroke, a piece of Latinx history comes to life and standing in front of one piece alone, allows the viewer to derive an endless number of relations.

Sometimes, the viewer derives the story the artist intended to tell; other times, they derive a new story, a story from their own perspective, motivating them to engage in prosocial behavior that contributes to the wellbeing and survival of their community. It can be argued that in many cases, murals, paintings, sketches, and other similar pieces of art, serve as motivative augmentals, bringing viewers into psychological proximity with previously established consequences. Additionally, they provide the opportunity for us to psychologically reaffirm our values, and subsequently, take action. The beauty of art on canvas is that it tells stories through metaphor, realism, and symbolism. For example, an image depicting a raised fist has been used in activism for decades, more recently, flooding social media news feeds. The raised fist has come to symbolize solidarity and support, and for many, represents BIPOC, historical social movements, activism pertaining to the murders of Black community members, and more. Thus, simply seeing the raised fist may evoke an entire network of events given one's history. Understanding the effects of art on canvas, paper, or any other surface will serve useful to leaders engaged in social movements and cultural change. A simple values slogan can easily be replaced with an image that has acquired perceptual functions that go above and beyond words. Moreover, careful consideration of all of the aforementioned tactics for prosocial persuasion may permit the development of educational resources that alter relations and practices that harm marginalized communities.

As we have argued throughout this paper, prosocial leadership for social change requires systemic, values-based strategy. To summarize, the critical components of this leadership approach includes: 1) studying the cultural milieu and increase awareness of social issues that affect their 
institution, 2) understanding how social issues and social identities intersect, 3) promoting active representation through inclusive hiring and institutional decision-making practices, 4) generating institutional verbal stimuli (i.e., policies, rules, and values) that create equitable, just, and inclusive practices, 5) communicating those policies and rules through persuasion and narrative to establish shared values, 6) implementing institutional analysis teams that identity points of departure and intervention within and external to the institution (including conflicting values and training), 7) identifying structures to measure change within the organization, and 8) putting plans in place to reevaluate processes.

\section{Conclusion}

The United States, and the world for that matter, faces a plethora of issues that require social movement. To reduce the effects of climate change, address the dangers of terrorism (including white supremacy and police brutality), and reduce the perpetuation of systemic oppression through the abuse of power, the development of a prosocial approach toward leadership is necessary. This calls for leaders who are able to bring communities together in solidarity and create inclusive environments that encourage members of our society to engage in values-based action that moves us, as a collective, toward shared prosocial values. As discussed, effective leadership relies on consistent focus on design and implementation of systemic contingencies that impact behavioral change within and outside the organization. Communication and value-oriented decision making are essential. As the forerunners of organizations, leaders must take notice of verbal networking systems that can promote behavioral change through authentic rhetoric and collective organizing. In doing so, they will be in a prime position to begin implementing the transformative change that the world needs now and well into the future. 


\section{Acknowledgements}

The authors would like to thank Dr. Mark Mattaini and José Ardila Sánchez for their valuable comments and suggestions throughout the preparation of this manuscript.

\section{Compliance with Ethical Standards}

No funding, grants, or other support was received to assist with the preparation of this manuscript.

The authors have no relevant financial or non-financial interests to disclose.

Ethics Approval: Not applicable as there were no human subjects. 


\section{References}

Anti-defamation League (ADL). (2020, May, 15). Year-over-year: white supremacists double down on propaganda in 2019. https://www.adl.org/media/14038/download

Alexander, M. (2010). The new Jim Crow: Mass incarceration in the age of colorblindness. New York: The New Press.

Americares. (2020, June 16). Hurricane Maria two-year report. https://www.americares.org/wp content/uploads/americares-hurricane-maria-2-year-report.pdf

Ardila Sánchez, J. G., Houmanfar, R. A., \& Alavosius, M. P. (2019). The effects of weather disasters on community resilience. Behavior and social issues, 28, 298-315. https://doi.org/10.1007/s42822 019-00015-w

Atkins, P.W.B., Wilson, D.S., \& Hayes, S.C. (2019). Introduction. In P.W.B. Atkins, D.S. Wilson, \& S.C. Hayes (Eds). Prosocial: Using Evolutionary Science to Build Productive, Equitable, and Collaborative Groups (pp. 1-9). Context Press.

Aristotle. Rhetoric. Trans. Roberts, W.R. (1954). New York, Modern Library.

Ayllon, T., \& Azrin, N. H. (1968). Reinforcer sampling: a technique for increasing the behavior of mental patients. Journal of Applied Behavior Analysis, 1, 13-20. https://doi.org/10.1901/jaba.1968.1-13

Baekgaard, M., \& George, B. (2018). Equal access to the top? Representative bureaucracy and politicians' recruitment preferences for top administrative staff. Journal of Public Administration Research and Theory, 535-550. https://doi.org/10.1093/jopart/muy038

Barnes-Holmes, D., Barnes-Holmes, Y., \& McEnteggart, C. (2020). Updating RFT (more field than frame) and its implications for process-based therapy. The Psychological Record, 70, 605-624. https://doi.org/10.1007/s40732-019-00372-3

Baum, W. M. (2017). Understanding behaviorism: Behavior, culture, and evolution (3rd ed.). Hoboken, NJ: Wiley. Retrieved from http://doi.org/10.1002/9781119143673 
Biglan, A. (2020). Rebooting capitalism: How we can forge a society that works for everyone. Selfpublished, Booknook.biz

Bradbury, M., \& Kellough, J.E. (2011). Representative bureaucracy: Assessing the evidence on active representation. The American Review of Public Administration, 41(2), 157-167. https://doi.org/10.1177/0275074010367823

Brethower, D. M. (2000). A systematic view of enterprise: Adding value to performance. Journal of Organizational Behavior Management, 20, 165-190. https://doi.org/10.1300/J075v20n03_06

Brown, T. (2014, April 11). Art is a weapon for social change. TEDx Talk, Xavier University. https://www.youtube.com/watch?v=7o6kbRBFLdI\&feature=emb title

Cárdenas, V., Ajinkya, J., \& Gibbs Léger, D. (2011). Progress 2050: New ideas for a diverse America. The Center for American Progress. https://www.americanprogress.org/issues/race/reports/2011/10/18/10477/progress-2050/

Centers for Disease Control and Prevention (CDC). (2020, June 25). COVID-19 in Racial and Ethnic Minority Groups. https://www.cdc.gov/coronavirus/2019-ncov/need-extra-precautions/racial ethnic-minorities.html

Cialdini, R.B. (1984). Influence: The psychology of persuasion. New York: Harper Collins.

Cialdini, R.B. (2011). Roots, shoots, and fruits of persuasion in military affairs. Analyses of Social Issues and Public Policy, 11(1), 27-30. https://doi.org/10.1111/j.1530-2415.2010.01227.x

Cialdini, R.B. (2016). Pre-Suasion: A revolutionary way to influence and persuade. London, Random House

Crenshaw, K. (1993). Mapping the margins: Intersectionality, identity politics, and the violence against women of Color. Stanford Law Review, 43, 1241-1299. https://doi.org/10.2307/1229039 
Crenshaw, K. (1989). Demarginalizing the intersection of race and sex: A black feminist critique of antidiscrimination doctrine, Feminist theory and antiracist politics. University of Chicago Legal Forum, 1989, 139-167. https://chicagounbound.uchicago.edu/uclf/vol1989/iss1/8/

Cutter, S.L., \& Emrich, C. (2005). Are natural hazards and disaster losses in the U.S. increasing? Eos, Transactions American Geophysical Union, 86(41), 381- 389. https://doi.org/10.1029/2005EO410001

Davis, A, Y. (2016). Freedom is a constant struggle: Ferguson, Palestine, and the foundations of a movement. Haymarket Books.

de Fernandes, R.C., \& Dittrich, A. (2018) Expanding the Behavior-Analytic Meanings of "Freedom": The Contributions of Israel Goldiamond. Behavior and Social Issues, 27, 4-19. https://doi.org/10.5210/bsi.v27i0.8248

DiAngelo, R. (2018). White fragility: Why it's so hard for white people to talk about racism. Beacon Press.

Esquierdo-Leal, J.L., Jacobs, N.N., \& Strauss, S. (2020). Prejudice in the health care system: Remediation strategies. In L. Benuto, M. P. Duckworth, A. Masuda, \& W.T. O’Donohue (Eds.), Prejudice, Stigma, Privilege, and Oppression: A behavioral health handbook. (pp. 337-359). Springer.

Festinger, L. (1957). A theory of cognitive dissonance. Evanston, Ill: Row, Peterson.

Florido, A. (2020). Political unrest in Puerto Rico after discovery of unused hurricane aid. National Public Radio (NPR). https://www.npr.org/2020/01/20/797996503/political-unrest-in-puerto-rico-after discovery-of-unused-hurricane-aid

Foucalt, M. (1982). The subject and power. Critical Inquiry, 8, 777-795. https://www.jstor.org/stable/1343197

Fulambarker, A. J. (2016). Valuing diversity in pursuit of social justice. In M. A. Mattaini \& C. 
Holtschneider (Eds.), Foundations of social work practice: A graduate text ( $5^{\text {th }}$ ed.), p. 99-115. NASW Press.

Ghezzi, E.L., Houmanfar, R.A., \& Crosswell, L (2020). The motivative augmental effects of verbal stimuli on cooperative and conformity responding under a financially competing contingency in an analog work task. The Psychological Record, 70, 411-431. https://doi.org/10.1007/s40732-020-00400-7

Gilbert, T. (2007). Human competence: Engineering worthy performance (Tribute Edition ed.). San Francisco: Pfeiffer.

Goldiamond, I. (1965). Justified and unjustified alarm over behavioral control. In O. Milton (Ed.), Behavior disorders: Perspectives and trends (pp. 237-261). New York: J. B. Lipincott.

Goldiamond, I. (1975). Singling out behavior modification for legal regulation: Some effects on patient care, psychotherapy, and research in general. Arizona Law Review, 17, 105-126. http://hdl.handle.net/10822/718351

Goldiamond, I. (1976). Protection of human subjects and patients: A social contingency analysis of distinctions between research and practice, and its implications. Behaviorism, 4, 1-41. https://www-jstor-org.unr.idm.oclc.org/stable/27758852

Goltz, S.M. (2020). On power and freedom: Extending the definition of coercion. Perspectives on Behavior Science, 43, 137-156. https://doi.org/10.1007/s40614-019-00240-z

Hamel, L., Wu, B., Brodie, M., Sim, S., \& Marks, E. (2018). One year after the storm: Texas gulf coast residents' views and experiences with Hurricane Harvey recovery.

\section{https://www.kff.org/other/report/one-year-after-storm-texas-gulf-coast-residents-views} experiences-hurricane-harvey-recovery/

Hayes, S. C., Barnes-Holmes, D., \& Roche, B. (2001). Relational frame theory: A post-Skinnerian account of human language and cognition. New York: Kluwer Academic/Plenum Publishers. 
Hayes, S.C, Strosahl, K.D., \& Wilson, K.G. (2012). Acceptance and commitment therapy: The process and practice of mindful change (2nd edition). New York, NY: The Guilford Press.

Herring, C. (2009). Does diversity pay?: Race, gender, and the business case for diversity. American Sociological Review, 74, 208-224. https://doi.org/10.1177/000312240907400203

Hill, C., Miller, K., Benson, K, \& Handley G. (2016, March). Barriers and bias: The status of women in leadership. https://www.aauw.org/app/uploads/2020/03/Barriers-and-Bias-nsa.pdf

Houmanfar, R.A., Alavosius, M.P., Morford, S.A., Herbst, S.A., \& Reimer, D. (2015). Functions of organizational leaders in cultural change: Financial and social well-being. Journal of Organizational Behavior Management, 35(1), 4-27. https://doi.org/10.1080/01608061.2015.1035827

Houmanfar, R., A. Ardila Sánchez, J. G., \& Alavosius, M. P. (in press). Role of cultural milieu in cultural change: mediating factor in points of contact. In T. Cihon, \& M. A. Mattaini (Eds.), Behavior Science Perspectives on Culture and Community. New York, NY: Springer.

Houmanfar, R.A., \& Mattaini, M. (2016). Leadership and cultural change: Implications for behavior analysis. The Behavior Analyst, 39, 41-46. https://doi.org/10.1007/s40614-016-0064-7

Houmanfar, R., \& Johnson, R. A. (2003). Organizational Implications of Gossip and Rumor. Journal of Organizational Behavior Management, 23(2-3), 117-138. https://doi.org/10.1300/J075v23n02_07

Houmanfar, R. A., Rodrigues, N.J. \& Smith, G.S. (2009). Role of Communication Networks on Behavioral Systems Analysis. Journal of Organizational Behavior Management, 29, 257-275. https://doi.org/10.1080/01608060903092102

Houmanfar, R. A., \& Rodrigues, N.J. (2012). The role of leadership and communication in organizational change. Journal of Applied Radical Behavior Analysis, 22-27. 
Hughes, J. (2009). A pilot study of naturally occurring high-probability request sequences in hostage negotiations. Journal of Applied Behavior Analysis, 42, 491-496. https://doi.org/10.1901/jaba.2009.42-491

Hughes, S., Barnes-Holmes, D., \& Vahey, N. (2012). Holding on to our functional roots when exploring new intellectual islands: A voyage through implicit cognition research. Journal of Contextual Behavioral Science, 1, 17-38. https://doi.org/10.1016/j.jcbs.2012.09.003

Institute for Criminal Justice Training Reform (IJCJTR). (2020, July). State law enforcement training requirements. https://www.trainingreform.org/state-police-training-requirements

Islam, S.N. \& Winkel, J. (2017). Climate change and social inequality (DESA Working Paper No. 152). Department of Economic and Social Affairs.

\section{https://www.un.org/development/desa/publications/working-paper/wp152}

Johnson, R. A., Houmanfar, R., \& Smith, G.S. (2010). The effect of implicit and explicit rules on customer greeting and productivity in a retail organization. Journal of Organizational Behavior Management, 30(1), 38-48. https://doi.org/10.1080/01608060903529731

Krapfl, J.E., \& Kruja, B. (2015). Leadership and culture. Journal of Organizational Behavior Management, 35, 28-43. https://doi.org/10.1080/01608061.2015.1031431

Levin, K., Cashore, B., Bernstein, B., \& Auld, S., (2012). Overcoming the tragedy of super wicked problems: Constraining our future selves to ameliorate global climate change. Policy Sciences, 45(2), 123-152. https://doi.org/10.1007/s11077-012-9151-0

Long, M.C., \& Bateman, N.A. (2020). Long-run changes in underrepresentation after affirmative action bans in public universities. Educational Evaluation and Policy Analysis, 1-20. https://doi.org/10.3102/0162373720904433

Mackun, P., \& Wilson, S. (2011, March). Population distribution and change: 2000 to 2010. United States Census Bureau. https://www.census.gov/library/publications/2011/dec/c2010br-01.html 
Malott, M.E. (2003). Paradox of organizational change. Reno, NV: Context Press.

Malott, M.E. (2019). How a few individuals brought about a cultural cusp: From a Mexican mural program to a movement. Perspectives on Behavior Science, 42, 773-814. https://doi.org/10.1007/s40614-019-00211-4

Mattaini, M.A., \& Aspholm, R. (2016). Contributions of behavioral systems science to leadership for a new progressive movement. The Behavior Analyst, 39, 109-121. https://doi.org/10.1007/s40614015-0043-4

Mattaini, M.A. (2013). Strategic nonviolent power: The science of Satyagraha. Edmonton, A.B.; AU Press. Morris, S., Adolphe, J. \& Salam, E. (2018). Does the new congress reflect you? The Guardian. https://www.theguardian.com/us-news/ng-interactive/2018/nov/15/new-congress-us-house of-representatives-senate

National Institute of Allergy and Infectious Diseases (NIH). (2018, March). Minority Health. https://www.niaid.nih.gov/research/minority-health

Nevin, J.A. (1996). The momentum of compliance. Journal of Applied Behavior Analysis, 29, 535-547. https://doi.org/10.1901/iaba.1996.29-535

Omvedt, G. (1973). Towards a theory of colonialism. Critical Sociology, 3(3). https://doi.org/10.1177/089692057300300301

Pelaez, M., \& Moreno, R. (1999). Four dimensions of rules and their correspondence to rule governed behavior: A taxonomy. Behavior Development, 8(1), 21-27. https://doi.org/10.1080/15021149.2013.11434459

Powell, J.A. (2020, June 16). Blog: All lives can't matter until Black lives matter too. Othering \& Belonging Institute. https://belonging.berkeley.edu/blog-all-lives-cant-matter-until-black-lives-matter-too 
Rafacz, S., Houmanfar, R., \& Smith, G., \& Levin, M. (2018). Assessing the Effects of Motivative Augmentals, Pay-for-Performance, and Implicit Verbal Responding on Cooperation. The Psychological Record, 69, 49-66. https:// doi:10.1007/s40732-018-0324-x

Skinner, B.F. (1938). The behavior of organisms: an experimental analysis. New York: Appleton-Century.

Skinner, B. F. (1948). Walden two. New York: Macmillan.

Smith, G. S., Houmanfar, R., \& Denny, M. (2012). Impact of rule accuracy on productivity and rumor in an organizational analog. Journal of Organizational Behavior Management, 32, 3-25. https://doi.org/10.1080/01608061.2012.646839

Smith, G. S., Houmanfar, R., \& Louis, S. J. (2011). The participatory role of verbal behavior in an elaborated account of metacontingency: From theory to investigation. Behavior and Social Issues, 20, 112 - 145. https://doi.org/10.5210/bsi.v20i0.3662

Stone, J., \& Moskowitz, G.B. (2011). Non-conscious bias in medical decision making: what can be done to reduce it? Medical Education, 45, 768-776. https://doi.org/10.1111/j.1365-2923.2011.04026.x

Tessum, C.W., Apte, J.S., Goodkind, A.L., Muller, N.Z., Mullins, K.A., Paolella, D.A., Polasky, S., Springer, N.P., Thakrar, S.K., Marshall, J.D., \& Hill, J.D. (2008). Inequity in consumption of goods and services adds to racial-ethnic disparities in air pollution exposure. Proceedings of the National Academy of Sciences of the United States of America (PNAS), 116(13), 1-6. https://doi.org/10.1073/pnas.1818859116

Tierney, K. (2006). Social inequality, hazards, and disasters. On Risk and Disaster: Lessons from Hurricane Katrina (pp. 109-128). In R. Daniels, D. Kettl, H. Kunreuther, \& A. Gutmann, On risk and disaster: Lessons from Hurricane Katrina. University of Pennsylvania Press. https://muse.jhu.edu/book/6210

Tierney, K. (2012). Disaster governance: social, political, and economic dimensions. Annu Rev Environ. Resource, 37, 341-363. https://doi.org/10.1146/annurev-environ-020911-095618 
Todorov, J.C. (2005). Laws and the Complex Control of Behavior. Behavior and Social Issues, 14, 86-91. https://doi.org/10.5210/bsi.v14i2.360

Toossi, M. (2006, November). A new look at long-term labor force projections to 2050. U.S. Bureau of Labor Statistics. https://www.bls.gov/opub/mlr/2006/11/art3full.pdf

U.S. Bureau of Labor Statistics. (2018, August). Labor force characteristics by race and ethnicity, 2017. https://www.bls.gov/opub/reports/race-and ethnicity/2017/home.htm\#: :text=The\%20employment\%E2\%80\%93population\%20ratio\%20wa ,\%2C\%205\%2C\%20and\%205a.)

U.S. Department of Education, National Center for Education Statistics (NCES). (2019). The Condition of Education 2019 (NCES 2019-144). https://nces.ed.gov/programs/coe/indicator csc.asp

United Stated Census Bureau. (2012, March 14). 1940-2010: How has America changed? https://www.census.gov/library/visualizations/2012/comm/1940-census-change.html 
Table 1

Proposed Behavior Analytic Accounts of Persuasive Tactics

\begin{tabular}{ccc}
\hline Aristotelian Perspective & Social Psychology (Cialdini) & Behavior Analytic Accounts \\
\hline Logos & Consistency & Behavioral momentum \\
Pathos & Reciprocation & Reinforcer Sampling \& \\
Ethos & Cooperation \\
& Authority & Credibility of the Speaker \\
\hline
\end{tabular}

